\title{
Spread Potential of Binucleate Rhizoctonia from Nursery Propagation Floors to Trays Containing Azalea Stem Cuttings and Sanitary Control Options
}

\author{
Warren E. Copes, USDA-ARS Thad Cochran Southern Horticultural Laboratory, Poplarville, MS 39470
}

\begin{abstract}
Copes, W. E. 2015. Spread potential of binucleate Rhizoctonia from nursery propagation floors to trays containing azalea stem cuttings and sanitary control options. Plant Dis. 99:842-847.

Binucleate Rhizoctonia sp. (BNR), the cause of web blight, can be spread on azalea stem cuttings into propagation houses, but also can be eliminated from stems by submerging cuttings in $50^{\circ} \mathrm{C}$ water for $21 \mathrm{~min}$. The overall objective was to evaluate risk of stem cuttings in trays becoming contaminated from inoculum on polypropylene fabric and gravel floors of propagation houses by evaluating four spread aspects in separate experiments. In experiment one, BNR was recovered from 1 to $50 \%$ samples from floor areas. In experiment two, BNR survival was higher under $70 \%$ shade than

full sun, with the presence of organic media than its absence, and on gravel than on fabric. In experiment three in both years, BNR was never recovered from peat in trays beside or on colonized floor materials. In experiment four, disinfestants greatly reduced BNR on ground fabric and significantly on gravel. Results show BNR persists in propagation houses, yet spread into propagation trays is very low. Results imply the importance of cleaning floor surfaces of organic matter. Disinfestants further reduce propagule survival, but may not completely eliminate BNR, especially on gravel.
\end{abstract}

Rhizoctonia web blight, caused by binucleate Rhizoctonia fungi (teleomorph Ceratobasidium D.P. Rogers), occurs annually on container-grown azalea (Rhododendron spp.) in the southern and eastern United States. AG-U was the predominate binucleate Rhizoctonia (BNR) recovered from symptomatic azalea leaves of plants grown in Alabama and Mississippi (16). Disease symptoms in decreasing order of frequency are completely necrotic leaves, leaf lesions, stem blight, and plant mortality, and typically appear from July to early September $(1,7,8,11,12)$. In the southeastern United States, the pathogen may be recovered from nonsymptomatic azalea foliage during the fall, winter, and spring months when web blight symptoms are not evident (6). Semihard stem cuttings are collected for commercial vegetative propagation in May to June. Unfortunately, a small percent of the azalea stem cuttings collected for propagation can harbor BNR. The industry practice is to stick harvested stem cuttings directly into trays filled with peat-based media without a sanitation treatment, thus allowing the pathogen to be introduced into propagation houses where it can colonize entire trays of cuttings. Copes and Blythe (4) showed that BNR can be eliminated by submerging terminal leafy cuttings of Rhododendron L. 'Gumpo White' azalea in $50^{\circ} \mathrm{C}$ water for $21 \mathrm{~min}$. Stem and leaf tissue of 12 azalea cultivars of 11 azalea families safely tolerated 20-min submersion in $50^{\circ} \mathrm{C}$ water with only a low likelihood of sustaining detrimental damage even with a 40-min submersion (5). The practice has not yet been adopted by the industry, although a few azalea and blueberry nurseries in the United States and in Peru are evaluating the practice.

Azalea stem cuttings typically develop a full root system within 9 to 12 weeks. After roots are well established, irrigation is switched from short-interval misting cycles to a once daily or as needed regime. In the southern United States, rooted cuttings often are retained in propagation houses until April the following year, when they are transferred into 2.7-liter containers in a pine bark medium. Houses commonly are cleaned of loose organic debris and left empty for 6 to 8 weeks before trays containing peat medium are set on the floor for the next propagation cycle

Corresponding author: W. E. Copes, Email: warren.copes@ars.usda.gov

Accepted for publication 11 November 2014.

http://dx.doi.org/10.1094/PDIS-09-14-0915-RE

This article is in the public domain and not copyrightable. It may be freely reprinted with customary crediting of the source. The American Phytopathological Society, 2015. and stem cuttings inserted into the growing medium. If stem cuttings free of BNR are used to produce rooted cuttings, further exclusion of the pathogen would be required from crop production areas. Information is not available that states if BNR survive in vacant propagation houses or whether inoculum on floors would contaminate propagation trays.

Sanitation is an accepted disease control practice in production facilities, yet a high degree of thoroughness requires greater justification $(9,18)$. The goal of this study was to understand the persistence of BNR to survive on floors in propagation houses, the potential risk for BNR inoculum present on floor substrates to contaminate Rhizoctonia-free stem cuttings, and the capability of sanitation methods to inactivate BNR on floor materials. The objective was approached as a four-part study: i) determine frequency of recovering BNR from polypropylene and gravel floors in commercial propagation houses, ii) determine survivability of BNR over a 6-week period on polypropylene and gravel floors, iii) determine probability of inoculum growing from the surface of polypropylene and gravel floors into propagation trays, and iv) evaluate efficacy of disinfestants and cleaning practices to eliminate BNR from polypropylene and gravel floors.

\section{Materials and Methods}

Recovery from floors. Floors of commercial propagation houses were sampled for recovery of naturally present Rhizoctonia spp., shortly after trays of rooted stem cuttings were removed from propagation houses. Floors of propagation houses were sampled in two commercial nurseries. Each house contained multiple cultivars. One nursery had houses with polypropylene fabric floors that were sampled on 31 March and 6 and 14 April, 2011, and 18 and 19 April, 2012. One nursery had houses with gravel beds, approximately 3 to $6 \mathrm{~cm}$ deep, that were sampled on 16 September, 2011, and 9 and 10 May, 2012. A replication consisted of a contiguous floor area of a propagation house occupied by one cultivar, from which 96 samples were selected from sixteen $1 \mathrm{~m}^{2}$ areas. A $1 \mathrm{~m}^{2}$ floor area was divided into a grid by placement of a $1 \mathrm{~m}^{2}$ frame constructed of $1.27 \mathrm{~cm}$ diameter PVC pipe. The grid pattern was created from tautly stretched string that divided the area into twenty-five $20 \times 20 \mathrm{~cm}$ squares with 16 intersect points. Two frames were alternately moved to opposite or adjacent sides of the other grid to transverse the space. Six intersect points were randomly selected per grid placement, resulting in a total of 96 sampling points. Directly beneath each preselected intersect, an autoclaved damp sponge $(1.5 \mathrm{~cm}$ wide $\times 3 \mathrm{~cm}$ long $\times 0.4 \mathrm{~cm}$ thick) held with sterile tweezers was firmly rubbed on the floor surface, then inserted in a $15 \mathrm{ml}$ autoclaved propylene tube. Additionally, a $1 \mathrm{~cm}$ length of transparent tape was stuck to the floor on the same spot and slid into 
the same propylene tube and capped. Samples were transported in a cooler and isolations done the following day, as explained further in the "Recovery of Rhizoctonia" section.

Rhizoctonia isolates were grown at $23^{\circ} \mathrm{C}$ in the dark. Colony phenology and presence of sclerotia were recorded after 28 days. Nuclear state was assessed with $200 \times$ to $400 \times$ magnification from five arbitrarily selected and spatially separated cells of mycelium stained with phenosafranin (one drop of 3\% $\mathrm{KOH}$ followed with a second drop of $0.6 \%$ phenosafranin), as previously described (6). Assessment of the nuclear state was repeated at a later date.

Colonization of floor materials. For all subsequent studies, floor materials were colonized with BNR AG-U, isolate JL1064Lzz12. Polypropylene fabric $2.54 \mathrm{~cm}$ wide strips were laid parallel and separated by $3 \mathrm{~cm}$ in a plastic tray $(25.4 \times 53.3 \times 5.7 \mathrm{~cm})$. Moist peat medium (Fafard 2B; Conrad Fafard, Agawam, MA) mixed with infested barley grains colonized by Rhizoctonia AG-U was piled on both sides of fabric strips so peat overlapped onto the edge of the fabric (4). Gravel with a mean weight of $0.9 \mathrm{~g}$ and a flattened shape that fit between two halves of a petri plate was dapped or sprayed with paint on one side for recognition in later recovery. Rhizoctonia infested barley grains were mixed with moist peat media in a plastic tray and gravel pieces buried so the top of the gravel was exposed to air. The air-peat interface improved colonization and adherence of Rhizoctonia on to fabric and gravel surfaces. Moisture of peat was misted for $6 \mathrm{~s}$ at 30 to $60 \mathrm{~min}$ intervals from 7 A.M. to 7 P.M. under a $70 \%$ shade cloth in a greenhouse until BNR mycelium had colonized floor materials. This technique was used in the "Survival on Floors" and "Spread on Floors" studies also.

For the "Sanitation Treatments" study, $2.2 \mathrm{~cm}^{2}$ pieces of fabric and relatively flat gravel was infested with Rhizoctonia AG-U, isolate JL1064Lzz12, in petri plates with half-strength PDA (hPDA). Autoclaved round wooden toothpicks were laid in parallel lines on the surface of hPDA to hold floor materials $2 \mathrm{~mm}$ above the surface of the agar. Agar blocks with hyphal tips were set at opposite sides of the petri plate. Mycelium growing below the substrates adhered to lower surfaces of floor materials. Once opposing mycelia converged at a minimum of $80 \%$ of the plate's diameter, in 3 to 4 days, the floor material was removed. Visible masses of mycelium were scraped from fabric and gravel materials with flat-ended student tweezers (No. 10-280, Fisher Scientific, Atlanta, GA) to reduce inoculum density.

Survival on floors. Experiments were performed from 1 June to 12 July in 2011 and 27 July to 6 September in 2012. A split plot in a completely randomized design was used to test two maintreatment pairs (full sun or $70 \%$ shade, and natural rainfall or rainfall with a daily cycle of $2 \mathrm{~min}$ irrigation at $2 \mathrm{~h}$ intervals from 7 A.M. to 7 P.M.) and two subtreatment pairs (polypropylene fabric or gravel floor material, and clean floors or floor material partially covered with $13 \mathrm{~cm}^{3}$ of peat media). Six replications of all four main-treatment combinations of sunlight or shade and rainfall or intermittent irrigation (24 main-treatment plots) were laid out in a completely randomized design. Main-treatment pairs were spaced by $0.65 \times 0.76 \mathrm{~m}$ within and between rows, respectively. Where applicable, irrigation emitters were $23 \mathrm{~cm}$ above the ground, and shade cloth hung $12 \mathrm{~cm}$ down all four sides of a $61 \mathrm{~cm}$ square and $26 \mathrm{~cm}$ high wooden frame. Each main-treatment contained all four subtreatment combinations. The four types of subtreatment pairs were separated by a $6 \mathrm{~cm}$ space and completely randomized in a square pattern centered around the irrigation riser if present and under the shade cloth if present. Each of the four subtreatments were further divided into three sample units that were randomized and collected at 2 week intervals. Three Rhizoctonia colonized fabric strips $(4.8 \times 20.3 \mathrm{~cm})$ were stapled to the bottom of a pressure-treated wooden frame $(15.2 \times 17.5 \mathrm{~cm}$ inner distance). A single fabric strip was removed with pliers at each sample time. Three separate frames $(5.1 \times 17.5 \mathrm{~cm}$ inner distance $)$ constructed of $4 \times 4 \mathrm{~cm}$ pressure-treated wood with polypropylene fabric stapled to the bottom were filled with $225 \mathrm{~g}$ of gravel; five colonized gravel pieces had been marked with a purple or orange paint spot. An individual frame of gravel was removed at each sampling time. All wooden frames were fixed to the ground by a $30.5 \mathrm{~cm}$ nail set through a hole in the frame. Air temperature $(\mathrm{T})$ and relative humidity $(\mathrm{RH})$ were measured at $25 \mathrm{~cm}$ above the ground in 2011 with a $\mathrm{HOBO}$ Pro V2 No. U23-011 (Onset, Pocasset, MA). T, RH, light in the photoactive region $(\mathrm{L})$ and rainfall were measured 25 and $0.6 \mathrm{~cm}$ above the ground (Decagon, Pullman, WA) in 2012. Weather variables were stored at 30-min intervals and daily minima, maxima, and averages were calculated. Gravel and fabric floor sections were sampled three times at 2 week intervals. Five small gravel pieces marked with paint were removed from each gravel treatment-replication and four $1.3 \times 2.0 \mathrm{~cm}^{2}$ pieces of fabric were cut from the fabric strip of each fabric treatment-replication. Recovery of Rhizoctonia is further explained in the "Recovery of Rhizoctonia" section.

Spread from floors. Experiments were performed from 27 June to 12 October in 2011 and 15 June to 11 October in 2012. Treatments consisted of two floor materials (polypropylene fabric, gravel), four quantities and placements of Rhizoctonia colonized floor material (no inoculum [check], one $1 \mathrm{~cm}^{2}$ fabric or one gravel piece placed between pairs of trays, two $1 \mathrm{~cm}^{2}$ fabrics or two gravel pieces with one placed below each tray, and one $7 \mathrm{~cm}$ length of $1 \mathrm{~cm}$ wide strip of fabric or six gravel pieces placed between pairs of trays). Six replications of each treatment were arranged in a completely randomized design in four columns and 12 rows on a greenhouse bench. Gravel floor material was autoclaved twice for $60 \mathrm{~min}$. Fabric floor material was soaked in $20 \%$ bleach solution for $10 \mathrm{~min}$, than rinsed with RO water. Azalea stem cuttings were collected in the morning on 27 June 2011 and on 14 June 2012, and submersed in $50^{\circ} \mathrm{C}$ water for $21 \mathrm{~min}$. Eight azalea stem cuttings per tray were inserted in peat substrate (Fafard 2B; Conrad Fafard, Agawam, MA) that filled two $17.8 \times$ $12.7 \times 3.5 \mathrm{~cm}$ (length $\times$ width $\times$ depth) trays, from here on referred to as tray pairs per treatment-replication. Tray pairs were separated by $2.5 \mathrm{~cm}$ and set on either a polypropylene fabric swatch $(31 \times$ $76 \mathrm{~cm}$ ) or on gravel that filled a $25.4 \times 25.4 \times 3.5 \mathrm{~cm}$ plastic tray. Flooring material was colonized with Rhizoctonia as described in the "Colonization of Floor Materials" section. Colonized floor pieces were placed either between the two trays adjacent to drain holes or below the trays in a central location. Azalea stem cuttings were mist irrigated for $10 \mathrm{~s}$ at $20 \mathrm{~min}$ intervals from 7 A.M. to 7 P.M. daily to induce root development. Greenhouse temperatures were set at 23 and $18^{\circ} \mathrm{C}$ during the day and night, respectively. One $0.7 \mathrm{~cm}$ diameter core of peat substrate was removed by each of two drain holes on the side of each tray where inoculum was placed and one core from the center of each tray with a metal scoopula down to the full depth of a tray from both trays per treatment-replication on 12 October 2011 and 11 October 2012, respectively, in the two experiments. The three cores from each tray were pooled as a composite sample in resealable bags. Scoopulas were flame sterilized between samples. Peat samples were plated on Ko and Hora (13). On 19 October 2011 and 18 October 2012, the original gravel and fabric colonized pieces were gathered and plated as described in the "Recovery of Rhizoctonia" section.

Sanitation treatments. Twelve sanitizer treatments were evaluated: sodium hypochlorite $(6.25 \%$ a.i.) (Bleach, The Clorox Co., Oakland, CA) at rates of 10,20 , and $30 \%$ product; hydrogen peroxide $(27.1 \%)$ and peroxyacetic acid (2.0\%) (ZeroTol 2.0, Biosafe Systems, LLC., East Hartford, CT) at rates of 1, 2, and 3\% product; n-Alkyl $\left(60 \% \mathrm{C}_{14}, 30 \%\right.$ $\mathrm{C}_{16}, 5 \% \mathrm{C}_{12}, 5 \% \mathrm{C}_{18}$ ) dimethyl ethylbenzyl ammonium chloride (10\% a.i.), and n-Alkyl $\left(68 \% \mathrm{Cl}_{2}, 32 \% \mathrm{C}_{14}\right)$ dimethyl benzyl ammonium chloride (10\% a.i.) (Green Shield, Whitmire Micro-Gen Research Laboratories, Inc., BASF Corp., St. Louis, MO) at rates of 0.4, 0.8, and 1.2\% product; and soap or steam (= soap-steam) at three nominal rates of scrubbing with liquid detergent (Ultra Palmolive, Colgate Palmolive Co., New York, NY) at three drops detergent per $100 \mathrm{ml}$ water, and steam (Shark Portable Stem Pocket System, Euro-Pro Operating, LLC., Boston, MA) for 15 and $60 \mathrm{~s}$. Treatments were applied in a randomized complete block design with six replications blocked over time within a single day. One colonized $1 \mathrm{~cm}^{2}$ fabric and one gravel piece were set in each of 72 aluminum foil trays. Disinfestants were mixed in sterile RO water and applied under a fume hood with a $500 \mathrm{ml}$ Kontes sprayer using pressurized air at $10 \mathrm{psi}$. Spray was applied in four sweeps to thoroughly wet material surfaces, then the substrate was flipped with tweezers and the other side thoroughly wetted. Steam treatments and scrubbing with detergent also were applied to both sides of the floor 
materials. For soap, a laboratory nylon bottle brush was dipped in detergent solution and the floor materials gently scrubbed. For steam, the steamer was turned on and allowed to reach a steady flow, then the wand was held $1 \mathrm{~cm}$ from the floor material for the allotted time. Materials were plated as described in the "Recovery of Rhizoctonia" section. The experiment was repeated.

Recovery of Rhizoctonia. All isolations were made on Ko and Hora agar (13) on $100 \mathrm{~mm}$ petri dishes and all transfers of mycelium were grown on hPDA. All tools (metal tweezers, stainless steel scissors, metal scoopula) were flame sterilized between handling of each sample. Petri plates were checked three to four times over 7 days at 1 to 3 day intervals for Rhizoctonia fungi by holding a plate toward fluorescent ceiling lights to observe mycelium growth habits. Mycelium traits characteristic of Rhizoctonia spp. were verified by microscopic examination, at $100 \times$ or $200 \times$, and included mycelium branch pattern, diameter, color, and cytoplasmic texture (6). Identification was verified by transferring mycelium tips to hPDA and allowing cultures to mature in approximately 2 weeks to check phenotypic characteristics.

Statistical analysis. BNR species recovery from floors of commercial propagation houses was explained by simple descriptive statistics. Frequency of Rhizoctonia AG-U survival from colonized floor pieces was initially assessed using the PROC UNIVARIATE procedure (SAS 9.3.1). Rhizoctonia AG-U recovery from floors was analyzed using the generalized linear regression procedure PROC GLIMMIX using a binomial distribution and a logit link function. Floor material, sunlight intensity, water forms, and organic presence were fixed effect binomial classification variables; biweekly sampling was a nominal variable; and Rhizoctonia recovery was a binary response variable. The random effect was a function of residuals with intercept as the subject. Residuals were graphically displayed to further assess distribution and presence of outliers. Pairwise comparison of treatments was performed using the $t$-test least significant difference in the least square means statement.

Analysis of sanitation treatments was performed using the PROC GLIMMIX procedure. Since over $50 \%$ of treatment response values had no recovery or total recovery of Rhizoctonia, a treatment mean was taken for all six replications over both experiments. Treatments with no recovery or total recovery of Rhizoctonia from all six replications in both experiments were removed from analysis because of zero variance. Preliminary analysis of full models was performed on square root transformed count data using PROC GLIMMIX to select model variables. Full model variables included two experiments, two floor materials, four sanitizers, three rates, the interaction between floor materials and sanitizers, and the interaction between floor materials, sanitizers, and rates. Fixed-effect classification variables were floor material (fabric, gravel) and sanitizer treatments (negative check, quaternary ammonium, peroxy compound, sodium hypochlorite, and soap-steam). Soap-steam at three rates was a fixed-effect nominal variable (soap and scrubbing, $15 \mathrm{~s}$ of steam, $60 \mathrm{~s}$ of steam) and disinfestants at three rates were fixed-effect ordinal variables $(1 \times, 2 \times$, and $3 \times$ a label rate). Subsequent analysis was performed on a reduced model with the response variable expressed as a binomial random variable (events / trials) that by default uses a binomial distribution and logit link function for computing the denominator degrees of freedom. Events is the number of trials with a positive recovery of Rhizoctonia and trials is the total number of replications. The interaction term of experiment, treatment, and substrate was used as the random effect. Pairwise comparison was performed using least square means specifying options of means, $t$-type confidence limits, estimates and standard errors, and least square means differences (LSD). For treatments excluded from the above analysis because of no recovery or total recovery of Rhizoctonia for all six replications or all replications of all rates in both experiments, one-sided confidence intervals were generated using the cumulative density function for the binomial distribution. Treatments with ' 0 ' and ' 1 ' values were compared with other treatments based on overlap of confidence intervals.

\section{Results}

Recovery from floors. Rhizoctonia was recovered from polypropylene fabric and gravel floors of propagation houses. Percent recovery ranged from 1 to $50 \%$ of the samples collected, but mostly were 8 to $19 \%$ of the samples (Table 1). The fabric floor section with $50 \%$ recovery was the only floor sampled before the leaf litter was removed by the grower. All BNR isolates recovered in the study were BNR fungi, and included multiple anastomosis groups (AG) based on phenotypic coloration traits on the reverse side coloration of mycelial cultures (6). BNR AG-U, AG-R, and AG-S exhibit a brown to dark brown coloration; AG-G exhibits a reddish brown coloration; and AG-A and AG-K exhibit a tan coloration. Isolates with a reddish brown and tan culture coloration predominated from fabric floors at Nursery A in 2011. Four color traits: brown, dark brown, reddish brown, and tan culture were evident from the fabric floors in propagation houses at Nursery A in 2012. Isolates recovered from gravel floors in Nursery B in 2012 predominately exhibited a dark brown culture coloration, but also had a reddish brown coloration.

Survival on floors. Rhizoctonia recovery was $100 \%$ from 10 pieces of polypropylene fabric and gravel floor on day 1. Rhizoctonia recovery declined by week 2 and further by weeks 4 and 6 from all treatments (Table 2). All interaction terms were not significant, including floor and sunlight $(P=0.6511)$, floor and peat $(P=0.4183)$, sunlight and peat $(P=0.3773)$, and sunlight and rainfall $(P=0.6096)$, so further

Table 1. Descriptive statistics of sampling logistics and binucleate Rhizoctonia fungi recovered from polypropylene fabric and gravel surfaces

\begin{tabular}{|c|c|c|c|c|c|c|c|c|c|c|c|}
\hline \multirow[b]{2}{*}{ Year } & \multirow[b]{2}{*}{ Nursery } & \multirow[b]{2}{*}{ Cultivarv } & \multirow[b]{2}{*}{$\begin{array}{c}\text { Floor } \\
\text { material }\end{array}$} & \multirow{2}{*}{$\begin{array}{c}\text { Days after } \\
\text { cuttings } \\
\text { removed }\end{array}$} & \multirow[b]{2}{*}{$\begin{array}{c}\text { Number } \\
\text { samples taken }\end{array}$} & \multirow[b]{2}{*}{$\begin{array}{c}\text { Number isolates } \\
\text { recovered }\end{array}$} & \multicolumn{4}{|c|}{ Color on reverse side of culture } & \multirow[b]{2}{*}{$\begin{array}{c}\text { Number } \\
\text { binucleate isolate }\end{array}$} \\
\hline & & & & & & & Brown & $\begin{array}{c}\text { Dark } \\
\text { brown }\end{array}$ & $\begin{array}{c}\text { Reddish } \\
\text { brown }\end{array}$ & Tan & \\
\hline 2011 & $\mathrm{~A}$ & $\begin{array}{l}\text { Delaware } \\
\text { Valley White }\end{array}$ & Fabric & 5 & 96 & 8 & 0 & 0 & $6 / 3 \mathrm{~s}^{\mathrm{x}}$ & 2 & 8 \\
\hline 2011 & A & Gumpo White & Fabric & 7 & 96 & 9 & 0 & 0 & 5 & 4 & 9 \\
\hline 2011 & A & Wakaibishu & Fabric & 2 & 96 & 1 & 0 & 0 & 0 & 1 & 1 \\
\hline 2011 & $\mathrm{~B}$ & Moonlight & Gravel & 5 & 96 & 8 & $\mathrm{dm}^{\mathrm{y}}$ & $\mathrm{dm}$ & $\mathrm{dm}$ & $\mathrm{dm}$ & 8 \\
\hline 2011 & $\mathrm{~B}$ & Prince & Gravel & 2 & 96 & 3 & $\mathrm{dm}$ & $\mathrm{dm}$ & $\mathrm{dm}$ & $\mathrm{dm}$ & 3 \\
\hline 2012 & A & Gumpo Pink & Fabric & 8 & 96 & 15 & $3 / 1 \mathrm{~s}$ & $10 / 9 \mathrm{~s}$ & 1 & 1 & 15 \\
\hline 2012 & A & Gumpo White & Fabric & 6 & 96 & 18 & $4 / 1 \mathrm{~s}$ & $3 / 3 \mathrm{~s}$ & 2 & 8 & 18 \\
\hline 2012 & A & Wakaibishu & Fabric & 1 & 96 & 48 & $20 / 1 \mathrm{~s}$ & $6 / 4 \mathrm{~s}$ & $8 / 1 \mathrm{~s}$ & 9 & $43^{z}$ \\
\hline 2012 & B & Angel & Gravel & 4 & 96 & 18 & 0 & $15 / 12 \mathrm{~s}$ & 2 & 1 & 18 \\
\hline 2012 & B & Chiffon & Gravel & 2 & 96 & 16 & 4 & $6 / 4 \mathrm{~s}$ & $3 / 1 \mathrm{~s}$ & 0 & $13^{z}$ \\
\hline 2012 & B & Coral & Gravel & 3 & 96 & 11 & 0 & $6 / 5 \mathrm{~s}$ & $2 / 1 \mathrm{~s}$ & 0 & $8^{z}$ \\
\hline
\end{tabular}

${ }^{\mathrm{v}}$ Azalea cultivars (Rhododendron spp. L.) of rooted stem cuttings that were removed prior to sampling that area.

${ }^{\mathrm{w}}$ Days since trays of rooted cuttings were removed from the propagation house when samples were collected.

${ }^{x}$ Number of total isolates / number of isolates that produced psuedosclerotia (s).

y Data were collected, but data sheet was misplaced (data missing, $\mathrm{dm}$ ).

z A lower number of isolates assessed to have a binucleate state than the number of isolates recovered was due to isolates dying while maintaining cultures. 
analysis was performed on main factors only. Rhizoctonia recovery was significantly lower between week 6 and $2(P=0.0069)$, between fabric floors and gravel floors $(P=0.0098)$, between full sunlight and $70 \%$ shade $(P \leq 0.0001)$, and between absence and presence of peat $(P=0.0170)$ (Table 2$)$. Rhizoctonia recovery was not significantly different between week 6 and week $4(P=0.9260)$ and between rainfall and rainfall with irrigation $(P=0.5433)$.

Mean \pm standard error of temperature and relative humidity between 7 A.M. and 7 P.M. in 2011 was $32.1^{\circ} \mathrm{C} \pm 0.15$, and $61.4 \% \pm$ 0.67 , respectively. Mean \pm standard error of temperature, relative humidity, and light intensity within the visible range between 7 A.M. and 7 P.M. in 2012 was $29.8^{\circ} \mathrm{C} \pm 0.16,75.4 \% \pm 0.56$, and $413.9 \mathrm{~W} / \mathrm{m}^{2} \pm$ 10.3 , respectively. A total of nine rainfall events from 0.3 to $1 \mathrm{~cm}$, three rainfall events from 2 to $3.5 \mathrm{~cm}$, and two rainfall events greater than $9 \mathrm{~cm}$ were recorded from 27 July to 6 September in 2012 .

Spread from floors. No Rhizoctonia isolates were recovered from peat media sampled from inside trays that contained rooted azalea stem cuttings that sat beside or over colonized fabric or gravel floor pieces for 107 and 119 days in 2011 and 2012, respectively. At the end of the trial, Rhizoctonia isolates were recovered from 11 and $55 \%$ of the original colonized fabric and gravel pieces, respectively, in 2011; and from 88 and $94 \%$ of the original colonized fabric and gravel pieces, respectively, in 2012.

Sanitation treatments. Due to the large number of treatments with a mean of 0 or 1, equaling 0 or $100 \%$ recovery, respectively, of Rhizoctonia spp. from all replications, treatments were averaged over experiments. Check treatments on fabric and gravel in both experiments had a mean of 1 and sodium hypochlorite on fabric at all rates in both experiments had a mean of 0 ; as a result, both were removed from the main statistical analysis. The initial analysis of the full model was performed on square root transformed count data. Both interactive terms, floor material and sanitizers $(P=0.5109)$ and floor materials and sanitizers and rates $(P=0.9765)$, were not significant and had very small F-values less than 1 , so were dropped. Further analysis was performed on events / trials response variables. Dose within floor material times treatment interaction was not significant $(P=0.8952)$, so was dropped from the model. In the final model, treatment means were averaged over rates. Floor materials $(P=0.0809)$ and treatments within floor materials $(P=0.0508)$ were significant but only at an alpha $=0.10$. The same probability was used to determine significance in the cumulative density function. Rhizoctonia recovery was not significantly different between the soap-steam and control (water) treatments for both fabric and gravel materials
(Table 3). The mean \pm standard deviation of temperature at $1 \mathrm{~cm}$ distance from the end of the steam wand for five replications after $15 \mathrm{~s}$ was $45.2^{\circ} \mathrm{C} \pm 1.30$ and after $60 \mathrm{~s}$ was $49.2^{\circ} \mathrm{C} \pm 0.45$. On fabric floor material, the three disinfestants were significantly different from the control and the soap-steam treatments, but were not different from each other based on LSD pairwise comparisons and overlap of confidence intervals (Table 3 ). On gravel, the three disinfestants caused a significantly higher inactivation of Rhizoctonia AG-U than soap-steam sanitation treatments, based on LSD pairwise comparison. However, based on $90 \%$ confidence intervals, only the peroxy compound and sodium hypochlorite caused significantly higher inactivation than the control treatment while quaternary ammonium treatments were not different from the control.

\section{Discussion}

BNR fungi were recovered from the surfaces of polypropylene fabric and gravel floors of commercial propagation houses containing azalea cultivars susceptible to Rhizoctonia web blight. This demonstrates that potential exists for BNR to contaminate new stock of pathogen-free azalea stem cuttings stuck in rooting media in trays set on those floors. Based on phenotypic culture traits, multiple AGs were recovered from the propagation floors, which is representative of BNR AG's found to cause Rhizoctonia web blight on azalea (6).

Propagation houses in the southeastern United States are commonly left empty for 6 to 8 weeks between crops from April into June. Often, plastic roof covers are completely removed, which prompted the question, to what degree would UV waves from sunlight affect survival of BNR mycelium? Rhizoctonia density did decline dramatically over a 6 week period (Table 2). The degree of decline supports the concept that exposure to sunlight and natural ambient conditions reduces survival of BNR, but the decline was not enough to eliminate the pathogen. One explanation for limited survival is mycelium of BNR survives in protected niches, such as between fabric overlap and on the underside of gravel.

Sanitation is a well-accepted general practice for reducing spread of many plant pathogens (9). Its importance is particularly emphasized in propagation facilities, because of the potential for large loss of juvenile plant material. General recommendations are to clean and disinfest production areas between crops, limit foot traffic, use clean potting media and rooting trays, use a water source free of pathogens, adjust misting to prevent desiccation of cuttings without over saturating the media, and apply fungicides $(2,14,17,19)$. Industry acceptance of

Table 2. Comparisons of the mean recovery of Rhizoctonia between ordinal or categorical levels within main treatments of week (over time), floor material of propagation houses, sunlight intensity, regularity of moisture events, and the presence of organic matter

\begin{tabular}{llcccc}
\hline Factor & \multicolumn{1}{c}{ Treatment $^{\mathbf{v}}$} & Mean $^{\mathbf{w}}$ & Mean probability $^{\mathbf{x}}$ & 95\% confidence intervals & Pairwise comparison $^{\mathbf{y}}$ \\
\hline Week & 0 & 1.000 & 1.000 & $0.7791-1.0000^{\mathbf{z}}$ & - \\
& 2 & 0.396 & 0.059 & $0.0480-0.0714$ & $\mathrm{~A}$ \\
& 4 & 0.251 & 0.039 & $0.0303-0.0503$ & $\mathrm{~B}$ \\
\multirow{2}{*}{ Floor } & 6 & 0.250 & 0.038 & $0.0299-0.0494$ & $\mathrm{~B}$ \\
& Gravel & 0.351 & 0.053 & $0.0441-0.0630$ & $\mathrm{C}$ \\
Light & Fabric & 0.256 & 0.038 & $0.0304-0.0464$ & $\mathrm{D}$ \\
& 70\% shade & 0.442 & 0.071 & $0.0608-0.0818$ & $\mathrm{E}$ \\
Moisture & Full sun & 0.156 & 0.028 & $0.0216-0.0358$ & $\mathrm{~F}$ \\
\multirow{2}{*}{ Organic } & Rainfall + irrigation & 0.309 & 0.046 & $0.0382-0.0561$ & $\mathrm{G}$ \\
& Rainfall & 0.289 & 0.043 & $0.0352-0.0521$ & $\mathrm{G}$ \\
& Peat Medium & 0.341 & 0.052 & $0.0310-0.0624$ & $\mathrm{I}$ \\
\hline
\end{tabular}

v Physical and environmental factors evaluated for survival and recovery of Rhizoctonia AG-U mycelium include: over time, from gravel and polypropylene fabric floors, under $70 \%$ shade and full sunlight, under rainfall and irrigation run for 2 min at $2 \mathrm{~h}$ intervals from 7 A.M. to 7 P.M., and with the presence and absence of peat media.

${ }^{\text {w }}$ Mean of Rhizoctonia recovery for each respective treatment. This data are only for visual comparison with the mean probability shown in the next column.

x Mean probability of Rhizoctonia recovery from each respective treatment that was calculated using the inverse link function of the treatment estimates on the logit scale.

y Pairwise comparison between levels of a factor based on least significant difference from $t$-tests. Levels with the same letter are not significantly different at $P=0.05$. Since interaction terms were not significant, each factor was evaluated separately and different letter sets used per factor.

${ }^{z}$ Since a mean of 1 has zero variance, a pairwise comparison was not determined and treatment differences will be based on confidence intervals. A one-sided confidence interval was calculated using a binomial cumulative distribution for the mean of 1 , which indicates $95 \%$ confidence interval is between 0.7791 and $1(n=12)$. 
any practice, including sanitation, is based on actual or perceived risk versus expenditure. Costs of sanitation includes labor to remove debris, clean surfaces, and apply disinfestant products; plus the cost of disinfestant products. The actual cost of disinfestant is less of a concern than the prioritizing of one task over another during a busy time of year. It is common practice for azalea producers to remove fallen leaves and organic substrate, but detailed cleaning and applying disinfestants to floors is not routinely performed in the southern and eastern United States. The probability of contamination originating from floors was evaluated to help determine if the effort needed to thoroughly clean and sanitize floors is justified. The result of zero contamination of rooting trays from BNR infested floor substrates was unexpected, making justification more challenging. For none of the trays to become contaminated even though most floor substrates were still infested with the pathogen at the end of the trial meant that mycelial growth was arrested during the entire rooting periods of 12 and 15 weeks. Since moisture was not a limiting factor under $12 \mathrm{~h}$ of misting and temperatures were suitable for growth of BNR, nutrient availability may have been the main limitation restricting mycelium growth from crossing a short $1 \mathrm{~cm}$ distance. The colonized substrates used in the experiment were free of plant organic matter, such as dead leaf residual and rooting media. It is anticipated that the presence of dead azalea leaf matter would have provided nutrients that would promote mycelial growth capable of crossing a $1 \mathrm{~cm}$ distance, thus allowing contamination of rooting trays. Organic matter promoted survival of BNR in a costudy reported here, and dead azalea leaf matter was the preferred habitat niche for the year-round recovery of Rhizoctonia in container-grown azaleas (6).

This study does not fully demonstrate the importance of removing organic matter from floors to promote the natural decline of BNR. The fact that organic matter has been identified as a preferred habitat for growth and survival of the pathogen should be a concern $(6,15)$. Producers commonly use air blowers or brooms to clean dehiscent leaves and substrate from floor surfaces. Organic fines could still facilitate survival and growth of BNR and would be more difficult to remove than leaves. Organic fines may be difficult to remove with an air blower or broom, thus may require prior dry weather conditions to lessen weight and adhesion properties of fines. Alternatively, strong pressure water sprayers may be effective, but would require considerably more time to clean large areas. Reduction of fines that accumulate in gravel would require large volumes of water directed to flush organic debris from gravel beds.

Disinfestants are common sanitation tools for eliminating plant pathogens from equipment, production surfaces, and tools. Cayanan et al. (3) inactivated mycelium of $R$. solani in suspension with $14 \mathrm{mg}$ free $\mathrm{Cl}$ per liter with $10 \mathrm{~min}$ contact time. In the present study, disinfestants reduced recovery of BNR, but results differed with substrate. BNR attached to fabric was completely inactivated even at the standard rate of 1 part bleach to 9 parts water, but when the fungus was attached to gravel it was not fully inactivated even at a rate of 3 parts bleach to 7 parts water. Multiple reasons may be associated with the rate response. Incomplete wetting of fabric and gravel surfaces could allow some inoculum to escape, but this seems unlikely in this trial since materials were thoroughly wetted on both sides. Rhizoctonia spp. can produce densely aggregated mycelium cushions that potentially are resistant to chemicals (10). One possible explanation is mycelial cushions formed and adhered more quickly and densely on gravel versus polypropylene fabric. In preliminary trials, floor materials were exposed to $R h i$ zoctonia growth for several time durations, up to 3 weeks. A colonization period of 3 to 4 days was selected as most suitable for the disinfestant trials, because longer colonization periods of 7 or more days resulted in poor control from disinfestants on both substrates (data not shown), probably because of a more densely developed mycelium matting or cushion formation.

Scrubbing with soap or the usage of steam did not reduce pathogen survival enough to justify use of these sanitation methods. Steam is produced by heating water to $100^{\circ} \mathrm{C}$ and should be rapidly detrimental to Rhizoctonia viability. However, mean temperatures at $1 \mathrm{~cm}$ below the steam wand were 45 to $49^{\circ} \mathrm{C}$, which is considerably lower than $100^{\circ} \mathrm{C}$. The drop in temperature probably resulted from the mixing of ambient air as steam traveled down the wand. Water baths of $50^{\circ} \mathrm{C}$ eliminated Rhizoctonia from azalea stem cuttings, but required cuttings to be submerged for $20 \mathrm{~min}$ (4). In the case of the steamer, a 1 min exposure is too short of duration to inactivate BNR.

Based on all of the above results, recommendations would be to remove organic debris from propagation floors, preferably with removal of larger debris followed by pressure washing to remove smaller particles, then leave floors fallow for at least a 4 week period before the house is filled with the next crop of azalea stem cuttings. These recommendations are similar but more thorough than the practices currently followed by producers. Application of disinfestants would further minimize risk of pathogen survival, but may still not fully eliminate BNR, particularly from gravel. The goal of integrated disease management is to invest labor and chemical resources selectively but effectively at key points to reduce the risk of pathogen activities that promote disease potential.

Table 3. Pairwise comparisons of the mean probabilities of recovering Rhizoctonia from $1 \mathrm{~cm}^{2}$ fabric and gravel pieces colonized with a Rhizoctonia AG-U isolate and treated with a sanitizing practice or disinfestant

\begin{tabular}{llccc}
\hline Floor & Sanitizer treatment $^{\mathbf{w}}$ & Mean probability $^{\mathbf{x}}$ & 90\% confidence intervals & Pairwise comparison $^{\mathbf{y}}$ \\
\hline Fabric & Check & 1.000 & $0.7791-1.0000^{\mathrm{z}}$ & - \\
& Soap-steam & 0.775 & $0.4097-0.9449$ & $\mathrm{AB}$ \\
& Peroxy compound & 0.045 & $0.0035-0.3825$ & $\mathrm{C}$ \\
& Quaternary ammonium & 0.067 & $0.0100-0.3393$ & $\mathrm{C}$ \\
& Sodium hypochlorite & 0.000 & $0.0000-0.0798^{\mathrm{z}}$ & - \\
Gravel & Check & 1.000 & $0.7791-1.0000^{\mathrm{z}}$ & - \\
& Soap-steam & 0.995 & $0.6175-0.9965$ & $\mathrm{~A}$ \\
& Peroxy compound & 0.391 & $0.1231-0.7463$ & $\mathrm{BC}$ \\
& Quaternary ammonium & 0.532 & $0.1925-0.8447$ & $\mathrm{~B}$ \\
& Sodium hypochlorite & 0.096 & $0.0191-0.3697$ & $\mathrm{C}$ \\
\hline
\end{tabular}

\footnotetext{
${ }^{w}$ Sanitizer treatments include: sodium hypochlorite (6.25\% a.i.) (Bleach, The Chlorox Co., Oakland, CA); n-Alkyl $\left(60 \% \mathrm{C}_{14}, 30 \% \mathrm{C}_{16}, 5 \% \mathrm{C}_{12}, 5 \% \mathrm{C}_{18}\right)$ dimethyl ethylbenzyl ammonium chloride (10\% a.i.) and n-Alkyl $\left(68 \% \mathrm{Cl}_{2}, 32 \% \mathrm{C}_{14}\right)$ dimethyl benzyl ammonium chloride (10\% a.i.) (Green Shield, Whitmire Micro-Gen Research Laboratories, Inc., by BASF Corp., St. Louis, MO); hydrogen peroxide (27.1\%) and peroxyacetic acid (2.0\%) (ZeroTol 2.0, Biosafe Systems, LLC., East Hartford, CT); and soap-steam: scrubbing with liquid detergent (Ultra Palmolive, Colgate Palmolive Co., New York, NY) at three drops detergent per $100 \mathrm{ml}$ water or steam (Shark Portable Stem Pocket System, Euro-Pro Operating, LLC., Boston, MA).

x Mean probability of Rhizoctonia recovery after a sanitizer treatment that was calculated using the inverse link function of the treatment estimates on the logit scale.

y Pairwise comparison between levels of a factor based on $t$-tests, levels with the same letter are not significantly different at $P=0.10$.

$\mathrm{z}$ Since 0 and 1 had zero variance, a pairwise comparison was not determined and treatment differences will be based on confidence intervals. A one-sided confidence interval was calculated using a binomial cumulative distribution, which indicates the $90 \%$ confidence interval for a mean of 0 is between 0 and $0.0798(n=36)$ and for a mean of 1 is between 0.7791 and $1(n=12)$.
} 


\section{Acknowledgments}

I thank Debbie Boykin, Midsouth Area ARS Statistician, for statistical support in analyzing sanitation treatments. The research was supported through the United States Department of Agriculture, Agricultural Research Service, Thad Cochran Southern Horticultural Laboratory, Southern Horticultural Research Unit project number 6404-21430-001-00D.

\section{Literature Cited}

1. Benson, D. M., and Jones, R. K. 2001. Rhizoctonia web blight. Pages 63-64 in: Diseases of Woody Ornamentals and Trees in Nurseries. R. K. Jones and D. M. Benson, eds. American Phytopathological Society, St. Paul, MN.

2. Bilderback, T. E., and Jones, R. K. 2001. Horticultural practices for reducing disease development. Pages 387-398 in: Diseases of Woody Ornamentals and Trees in Nurseries. R. K. Jones and D. M. Benson, eds. APS Press, St. Paul, MN.

3. Cayanan, D. F., Zhang, P., Liu, W., Dixon, M., and Zheng, Y. 2009. Efficacy of chlorine in controlling five common plant pathogens. HortScience 44:157-163.

4. Copes, W. E., and Blythe, E. K. 2009. Chemical and hot water treatments to control Rhizoctonia AG-P infesting stem cuttings of azalea. HortScience 44: 1370-1376.

5. Copes, W. E., and Blythe, E. K. 2011. Rooting response of azalea cultivars to hot water treatment used for pathogen control. HortScience 46:52-56.

6. Copes, W. E., Garcia-Rodriguez-Carres, M., Toda, T., Rinehart, T. A., and Cubeta, M. A. 2011. Seasonal prevalence of species of binucleate Rhizoctonia fungi in growing medium, leaf litter, and stems of container-grown azalea. Plant Dis. 95:705-711.

7. Copes, W. E., and Scherm, H. 2005. Plant spacing effect on microclimate and Rhizoctonia web blight development in container-grown azalea. HortScience 40:1408-1412.

8. Copes, W. E., and Scherm, H. 2010. Rhizoctonia web blight development on container-grown azalea in relation to time and environmental factors. Plant Dis. 94:891-897.
9. Daughtrey, M. L., and Benson, D. M. 2005. Principles of plant health management for ornamental plants. Annu. Rev. Phytopathol. 43:141-169.

10. Dodman, R. L., and Flentje, N. T. 1970. The mechanism and physiology of plant penetration by Rhizoctonia solani. Pages 149-160 in: Rhizoctonia Solani, Biology and Pathology. J. R. Parmeter, ed. Univ. of Calif. Press, Berkeley, CA.

11. Frisina, T. A., and Benson, D. M. 1987. Characterization and pathogenicity of binucleate Rhizoctonia spp. from azalea and other woody ornamental plants with web blight. Plant Dis. 71:977-981.

12. Frisina, T. A., and Benson, D. M. 1989. Occurrence of binucleate Rhizoctonia spp. on azalea and spatial analysis of web blight in container-grown nursery stock. Plant Dis. 73:249-254.

13. Ko, W., and Hora, F. K. 1971. A selective medium for the quantitative determination of Rhizoctonia solani in soil. Phytopathology 61:707-710.

14. Litterick, A. M., McQuilken, M. P., and Holmes, S. J. 1995. Sources of Rhizoctonia species in ericaceous plant nurseries. J. Plant Dis. Prot. 102: 441-444.

15. Papavizas, G. C. 1970. Colonization and growth of Rhizoctonia solani in soil. Pages 108-122 in: Rhizoctonia Solani, Biology and Pathology. J. R. Parmeter, ed. Univ. of Calif. Press, Berkeley, CA.

16. Rinehart, T. A., Copes, W. E., Toda, T., and Cubeta, M. A. 2007. Genetic characterization of binucleate Rhizoctonia species causing web blight on azalea in Mississippi and Alabama. Plant Dis. 91:616-623.

17. Rutherford, E., Epton, H. A. S., and Benton, R. A. 1989. Improvement of propagation by use of fungicides. Develop. Soil Sci. 18:371-376.

18. Stephens, C. T., Herr, L. J., Schmitthener, A. F., and Powell, C. C. 1983 . Sources of Rhizoctonia solani and Pythium spp. in a bedding plant greenhouse. Plant Dis. 67:272-275.

19. Williams-Woodward, J., and Jones, R. K. 2001. Sanitation: Plant health from start to finish. Pages 384-386 in: Diseases of Woody Ornamentals and Trees in Nurseries. R. K. Jones and D. M. Benson, eds. APS Press, St. Paul, MN. 